\title{
EFFECT OF VELOCITY ON ROLL/SLIP FOR LOW AND HIGH LOAD CONDITIONS IN POLYMER COMPOSITE
}

\author{
J. Sukumaran ${ }^{1}$, M. Ando ${ }^{2}$, V. Rodriguez ${ }^{1}$, P. De Baets ${ }^{1}$ \\ ${ }^{1}$ University of Gent, Department of Mechanical Construction and Production, Sint-Pietersnieuwstraat, 41, \\ 9000 Gent, Belgium \\ ${ }^{2}$ Szent István University, GÉTI, Páter Károly utca 1. 2100 Göldöllő, Hungary
}

\begin{abstract}
In the last decade polymer composites are often used without lubrication on both low and high speed applications. Some of the application areas are marine, automotive and agriculture used as bearings and cams where roll-slip is the dominant mechanism. Limited studies are made for composites relating such applications where rolling/sliding condition influences the tribological behavior of the material. Investigating the roll-slip phenomenon for identifying the influence of velocity on frictional behavior can mark a boundary to map the use of composites with respect to its application. Moreover, the design of the material can be optimized to match the operating conditions. In the current research the polymer composite (with polyester matrix) has been tested under rolling-sliding condition for two different loads with $61 \mathrm{~N}$ and $210 \mathrm{~N}$ and with different speeds ranging from $10 \mathrm{rpm}$ to $700 \mathrm{rpm}$. Ideal conditions in terms of roughness, slip ratio, surface temperature and ambient temperature were maintained to reduce the frictional heating. Using a $20 \%$ slip ratio the behavior of the material was observed for the tribological characteristics where the rate of increase of friction force follows a exponential pattern with increasing speeds. Nevertheless, on testing with high speeds a steady rate of increase in the friction curve was observed. Friction behavior of composites under different speeds is briefed with the microstructural characteristics for low and high loads.
\end{abstract}

Keywords Rolling/sliding, polyester composites, friction force, effect of velocity

\section{INTRODUCTION}

Composite are adopted as a solution to new materials in the bearing industry for dry running applications in-order to avoid complex lubricating system [1]. Fiber composites are the preferred materials in such applications for the versatility in fibre orientation, fibre usage and volume fraction of the composite which can be altered according to the requirement [2]. The fiber composites are preferred for their relatively high young's modulus. Apart from the fibbers and resins, fillers are added as a lubricant to have better frictional behaviour [3- 5]. Internal lubricant such as PTFE is generally used as friction modifiers. Low coefficient of friction, resistance to stick-slip and high anti-adhesive property of PTFE makes it a suitable material as friction modifiers in bearings [6,7]. It was also found that the fiber orientation normal to the sliding direct has produced favourable friction conditions [8].

The influential parameters mostly investigated in a tribological system of polymer composites are the velocity and the load governed by the visco-elastic property of the material[8]. Even though standard rules dictate the tribological behaviour, the system as a whole does not permits to have the same results for the similar materials at same test condition [3]. Previous research by El Syed et al [1] with fiber reinforced polymer composites has produced high coefficient of friction for low pv ratio which is explained by the softening behaviour of the composite. Contradicting behaviour on the tendency of the friction co-efficient was observed by Su et al on investigation PTFE composites [6]. The friction coefficient varies inevitably independent to the applied load where materials tested at high speeds have low coefficient of friction due to the polishing effect. Apart from the load and the velocity the frictional heating plays a vital role by having a deposit of transfer layer in the counterface material and thus reducing the coefficient of friction.

The deposit of transfer layer is a system and the material dependant, early research by El-Tayeba et al on polyester composites with sugarcane fibre and glass fibre has dissimilar results due to the back transfer of polymers in one of the materials by adhesion process [9]. Since a clear boundary has not been characterized between the presence of transfer layer and the back transfer, the material interaction rather seem to be uncertain. The current research has the underlying principle of interaction between compositemetal pairs rather than composite-composite pairs. And this is maintained by avoiding the phenomenon of transfer film and isolating the temperature variable (By having approximately a constant contact temperature along the test).

In the tribological system the most commonly occurring phenomenon is sliding and most of the researches correspond to pure sliding condition where adhesion plays a vital role. Apart from sliding the rolling 
phenomenon exhibits in certain engineering components like gear, cams and rollers which tend to have rollslip. This rolling to sliding at the same time has deformation as the additional mechanism to complicate the investigation. Only few researches have been conducted on polymer-metal and polymer-polymer contacts [10-13] thus leading to a situation of testing the interaction between composite-metal pair on rolling/sliding conditions.

\section{EXPERIMENTAL}

\subsection{Materials}

A combination of thermoset composite against steel is used for the current investigation. Commercially available polyester fiber reinforced polyester (Orkot) is used in place of the thermoset composite and $40 \mathrm{CrMn}$ tool steel is used as a counterface material. Orkot (Trelleborg $A B$ ) is a specially designed material used for bearings, the composite comprises polyester fabric with thermoset resin and PTFE as a internal lubricant. The material properties for the thermoset composite and the counterface material are given in Table 1. The used composite samples are in the form of a ring where a holder is used under press fit to fix the test material to the setup on running against solid counterface material. The composite ring has $8 \mathrm{~mm}$ width and $5 \mathrm{~mm}$ thickness. The diameter of the contacting surface for the composite and the counterface material is $90.12 \& 74.93 \mathrm{~mm}$.

Table 1. Properties of the used materials.

\begin{tabular}{|l|c|c|}
\hline Properties & $\mathbf{4 0}$ CrMn & Orkot \\
\hline Yield strength $[\mathrm{MPa}]$ & 415 & 55 \\
\hline Young's modulus $[\mathrm{GPa}]$ & 205 & 3.3 \\
\hline Impact Strength $\left(\right.$ Charpy) $\left[\mathrm{kJ} / \mathrm{m}^{2}\right]$ & 590 & 122 \\
\hline Hardness & $220 \mathrm{HB}$ & 100 Rockwell M \\
\hline Maximum allowable service temp. $\left[{ }^{\circ} \mathrm{C}\right]$ & - & 130 \\
\hline
\end{tabular}

\subsection{Test device}

Although standards are available to study the frictional behaviour of materials for sliding phenomenon, the involvement of rolling in some cases urges the materials to be tested for roll-slip. A twin-disc is the apt model to investigate the contact between composite-metal pairs during rolling/sliding condition. For the current investigation the modified twin-disc setup at Laboratory Soete is used to test composite against tool steel for a specific slip ratio which is achieved by the difference in the diameter of the test disc and the counterface material disc. The required slip ratio is obtained by having different diameter of steel disc $\left(\mathrm{d}_{1}\right)$ and composite disc $\left(d_{2}\right)$, which can be calculated with (1):

$$
\mathrm{S}=\left(\frac{\mathrm{d}_{2}-\mathrm{d}_{1}}{\mathrm{~d}_{1}}\right) \cdot 100
$$

Torque meter attached to the shaft of the steel disc is used to measure the friction torque. Moreover, the temperature of the contact surface is measured using an infrared sensor and the normal load is induced by loading dead weights to the pivoted arm. Figure 1. shows the twin-disc setup used for testing the composite-metal pair.

All the measurements were recorded using online data acquisition system. Materials are tested with $20 \%$ slip ratio for five different speeds ranging from $10 \mathrm{rpm}$ to $700 \mathrm{rpm}$ for low load and high loading condition. A special program is developed (using labview) to test the material for different speeds. Initially a running-in is made for 16 minutes preceded by the measuring cycles where a specific time for conditioning is introduced for changing the speeds. Conditioning is done in order to avoid the transition during change in speed. In regards to the temperature measurement, the infra red sensor is located $180^{\circ} \mathrm{C}$ away from the instant of contact.

The friction from the bearings and seals of the machine has an influence on the measured friction torque and hence to have precise results a reference torque under no load condition is suplimented from the friction-torque obtained during loading. Moreover, the friction force is calculated from the friction torque and the diameter of the test disc (2).

$$
\text { Friction force }(N)=\frac{T(\mathrm{Nm})}{r(\mathrm{~m})}=\frac{\text { "Measurments"-Average of "reference Torque" }}{\text { radius of the steel wheel }}
$$




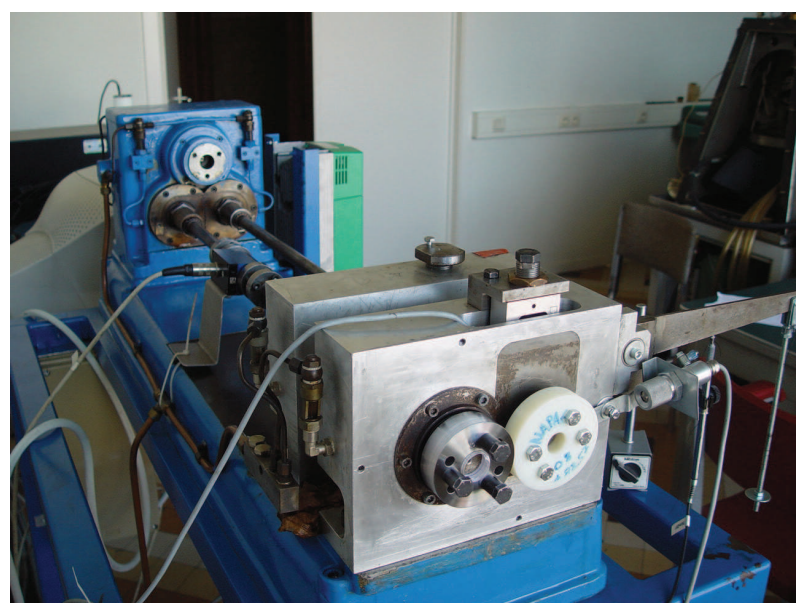

Figure 1. Shows the twin disc FZG test setup

Both the metal and composite samples were cleaned before and after the measurements. The contact surface of the counterface material is cleaned with metal sponge, acetone and alcohol (Loctite 7061), the same is used for the composite material except for the metal sponge which could change the surface parameter of the composite. Micrograph of the contact surface is taken at all intervals using a SFX microscope (Olympus) and a video camera (QICAM). Change is roughness of the contact surface is measured after every interval using a roughness tester (Homel).

\section{RESULT AND DISCUSSION}

Material behaviour on Hertzian non-conformal contacts plays a vital role in deciding the material behaviour for specific applications. Polyester composites were run against tool steel countersurface to test the tribological behaviour on rolling/sliding condition. Obtained results are the average of five measurements at every point in the curve. A deviation approximately $10 \%$ was observed which is very good in case of tribological testing. Five different speeds with 10,100, 200, 450 and $700 \mathrm{rpm}$ are used together with $61 \mathrm{~N}$ (maximum pressure is $77.23 \mathrm{MPa}$ ) and $210 \mathrm{~N}$ (maximum pressure is $143.30 \mathrm{MPa}$ ) loads to study the tendency of friction force. The friction force increases as the load is increased likewise the increase in speed tends to increase the friction force. Figure 2. illustrates the friction force as a function of speed for both low and high load condition.

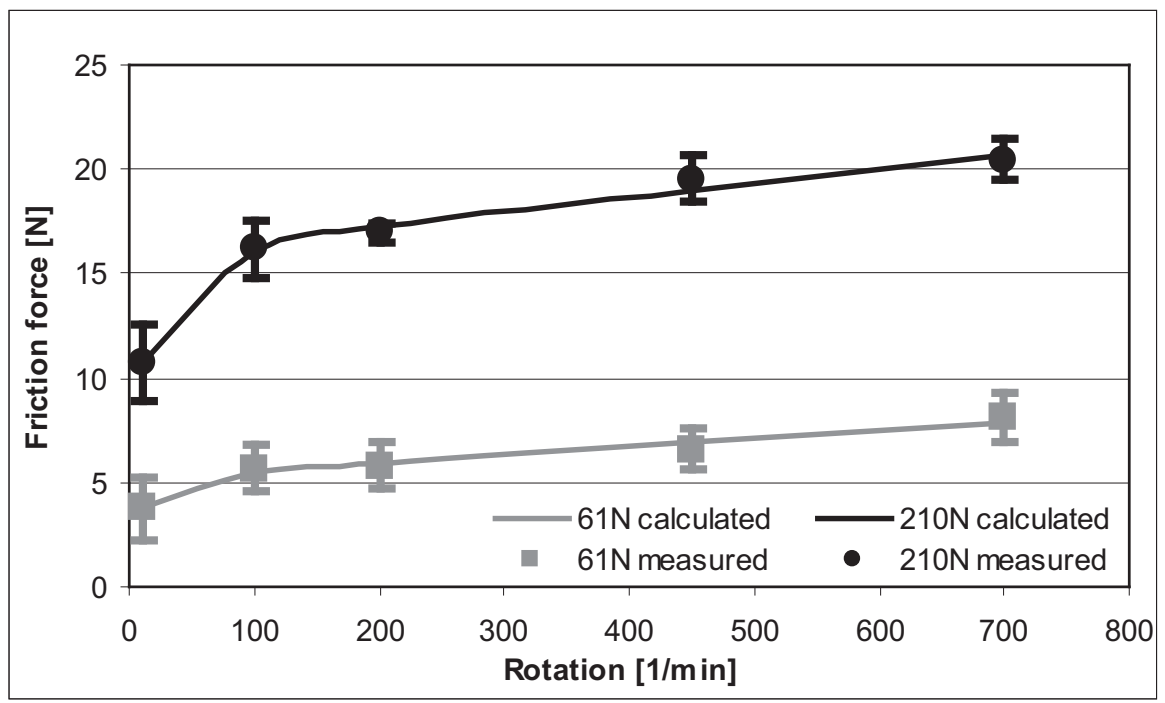

Figure 2. Friction force as a function of speed

The points in the plotted graph represents the experimental values and the curves are from the calculated functions. It is seen that the friction force is relatively less on low speeds and found to be rapidly increasing until a critical value (approximately 100-150 rpm) and saturates further to follow a linear increase to the corresponding speed. The rapid increase in friction force on low speeds is effective in high load condition relative to low load. The rapid increase in low speed can be explained with the time dependant strain 
response of the polymer in the reinforced composite. The overall tendency of the curve shows exponential behaviour of the materials on testing against steel. It is interesting that the friction force increases by approximately $51 \%$ from 10 to $100 \mathrm{rpm}$ on low and high load condition. In case of high speeds between 100 to $700 \mathrm{rpm}$ the friction force increases just $26 \%$ at high loads and $42 \%$ in low load. This tendency might have been produced by having large rolling resistance, and there is also some effect due to the stronger adhesion during high loads.

Table 2. illustrates the functions for the curves and their $R^{2}$ values where a linear increase in case of high load is seen and simultaneously the rate of increase in friction force is relatively more. But the high nominal values on changing to high speed since $100-700 \mathrm{rpm}$ is $26 \%$ which means, the material on high load is less sensitive to the speed relative to the low load.

Table 2. illustrates the functions for the curves and their $R^{2}$ values

\begin{tabular}{|l|l|l|}
\hline M238 and PA6 & Equation & $\mathbf{R}^{2}$ value \\
\hline $\mathbf{6 1} \mathbf{N}(\mathbf{7 7 . 2 3} \mathbf{~ M P a})$ & $F=3.367 \cdot\left(1-\mathrm{e}^{-0.0897 \cdot \mathrm{n}}\right)+0.004 \cdot \mathrm{n}+1.718$ & 0.8602 \\
\hline $\mathbf{2 1 0} \mathbf{N}(\mathbf{1 4 3 . 3 0} \mathbf{~ M P a})$ & $F=6.895 \cdot\left(1-\mathrm{e}^{-0.0256 \cdot \mathrm{n}}\right)+0.007 \cdot \mathrm{n}+9.082$ & 0.9656 \\
\hline
\end{tabular}

\subsection{Effect of the temperature}

Most of the studies on friction force are evaluated based on the temperature effects but in fundamental research isolating a variable gives much more valuable information to design the system and the material accordingly. In the current research the effect of temperature has been eliminated by using limited time of contact. Figure 3. (a) \& (b) shows the measured temperature as a function of speed where an increase in temperature of $2^{\circ} \mathrm{C}$ is observed in both low and high load condition. In previous research on rolling/sliding contacts of polymers the temperature increases over $80^{\circ} \mathrm{C}$ which has potent effect on the friction force but in our case the maximum attained temperature was $26{ }^{\circ} \mathrm{C}$ which has relatively less effect to consider friction heating to decide the tendency of the frictional curve. In most of the cases the tendency of the temperature curve is linear to the increasing speed but within a very limited range so to consider it as a major change in the temperature is not viable. Within the two degree increase in temperature higher temperature was observed in low loading condition. Temperature also has an effect on forming transfer layers in the counterface material, which was not observed in our case due to less friction heating and limited contact period. The transfer layer tends to have a condition where composite is tested against composite but in our case by avoiding such a phenomenon a real interaction between composite and metal are studied.
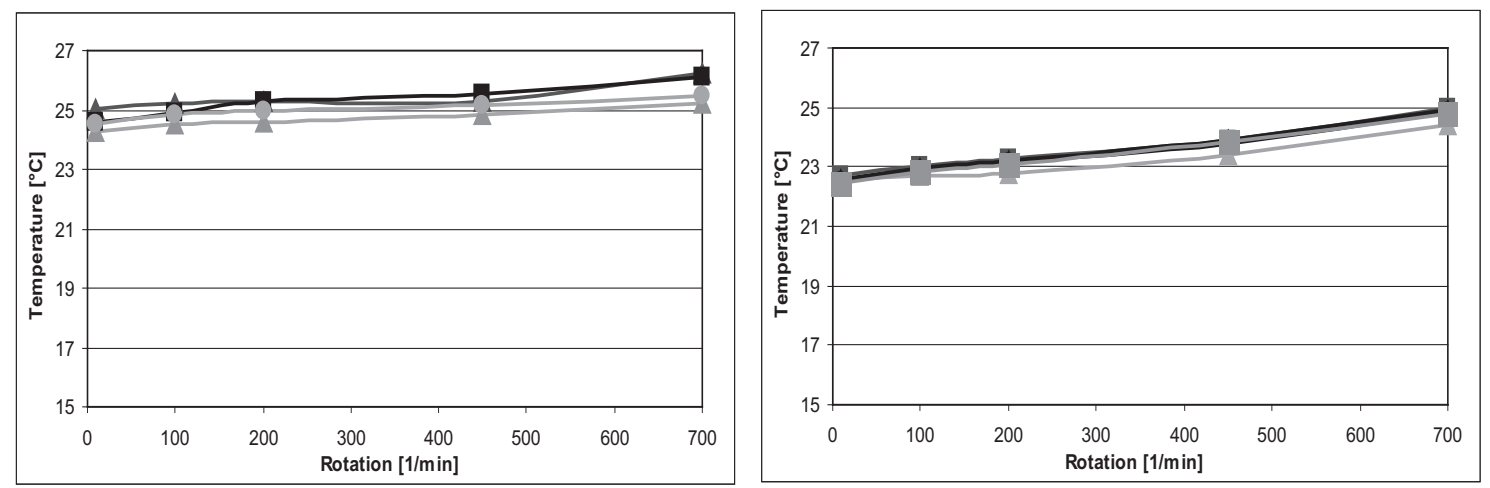

Figure 3. Measurements on temperature Vs speed (a) low loading condition (b) high loading condition

The deposition of transfer material on the counter face is critical which relies on the parameters like load and velocity activated by thermal effects. In most cases the transfer layers are very well present and in few cases the transfer layer cannot be seen due possible melting from the counterface material and transferred back to the polymer surface by adhesion. In the current research such complications were avoided and the result deliberates the influence of velocity without the aid of composite. Studies have proven that a deposit of atomic layer of plastic occurs during the first contact [14]. Nevertheless, even with an atomic layer of polymer on the counterface material the influencing factor affecting the friction force should be negligible.

\subsection{Micrograph}

Images were made on the contact surface using Olympus SRZ microscope before and after the testing. It is seen in Figure 4. (a) that a clean surface of the composite is seen before testing without any pits or 
damages. But, on the other hand images shown in Figure 4. (b) \& (c) from the tested surface displays pits and abraded surface.
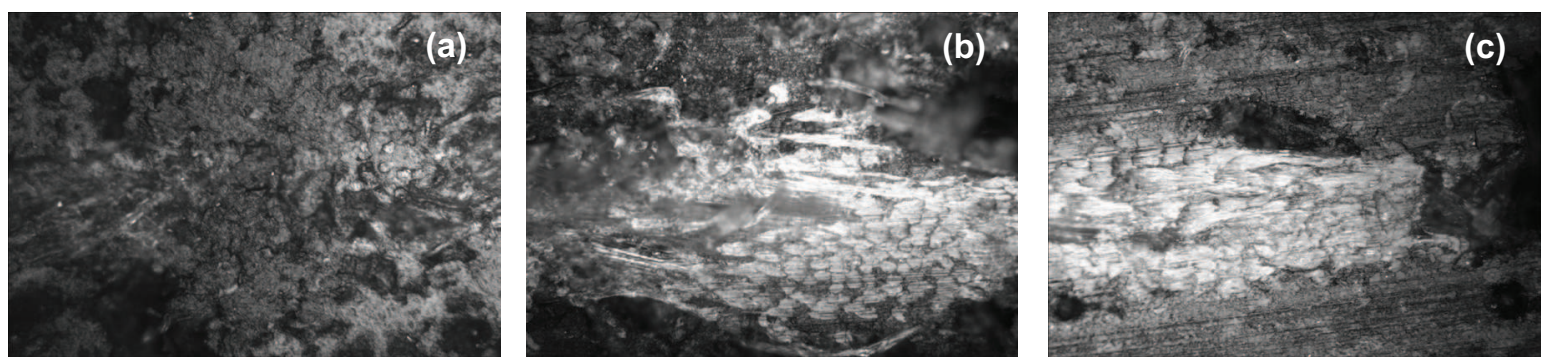

Figure 4. shows the contact surface of the composite (a) before contact (b) low load (c) high load

The scale like appearance on the contact surface is due to the aberration of thermoset leaving the matrix to expose and the pits are the places where the fibers tends to break leaving craters on the contact surface. Composite being the less hard material than the tool steel is expected to have considerable change in surface topography relative to the steel surface and hence the imaging is done only on composite surface. It is also seen from the image that the machine mark from the steel is impregnated in the composite. Comparing the image from both the loads not much difference is seen in the surface topography.

\section{CONCLUSIONS}

Composite - metal pair which has recently captured the bearing industry for dry running application has complex mechanism involved in briefing the friction behaviour of these materials. Results from previous researches focuses on sliding but roll-slip does occur in such composite-metal pairs in applications like bearings, gears and cams. Experiments for roll-slip phenomenon under different velocities in low and high load condition produce similar results with a change in the tendency of the friction curve along the test period. The friction force increases rapidly under low speed until 100rpm and above that until $700 \mathrm{rpm}$ the friction force increases linearly with increasing speed. Along the test cycle a combination of exponential and a linear behaviour of the friction curve was produced. Moreover, for the observed tendency the material is less sensitive to the changing speed in case high load. For this result there is a minimal effect of the contact temperature (less than $2^{\circ} \mathrm{C}$ changing) because of the special test method and the environment. There was no goal to examined the wear but from the beginning the are some craters on the composite surface.

\section{NOMENCLATURE}

$$
\begin{aligned}
& F \text { - friction force } \\
& T \text { - friction torque } \\
& \text { Fn - normal load } \\
& R \text { - radius of the steel wheel } \\
& d_{1} \text { - diameter of the steel wheel } \\
& d_{2} \text { - diameter of the composite wheel } \\
& \text { PTFE - polytetrafluorethylene }
\end{aligned}
$$

\section{REFERENCES}

[1] El-Sayed A.A., El-Sherbiny M.G., Abo-El-Ezz A.S., Aggag G.A., Friction and wear properties of polymeric composite materials for bearing applications, Wear, 184(1), 45-53, 1995.

[2] Srivastava V.K., Pathak J.P., Friction and wear properties of bushing bearing of graphite filled short glass fibre composites in dry sliding, Wear 197(1-2), 145-150, 1996.

[3] Quintelier J., Online wear monitoring of polymer matrix composites with advanced measurement techniques, Ph.D Thesis, Gent University, 2007.

[4] Kishore, Sampathkumaran P., Seetharamu S., Thomas P., Janardhana M., A study on the effect of the type and content of filler in epoxy-glass composite system on the friction and slide wear characteristics, Wear, 259(1-6), 634-641, 2005. 
[5] Zhang X, Pei X, Wang Q. Friction and wear properties of combined surface modified carbon fabric reinforced phenolic composites. European Polymer Journal 44, 2551-2557, 2008.

[6] Su F., Zhang Z.Z., Guo F., Men X.H., Liu W.M., Friction and wear properties of fabric/phenolic composites with plasma treated-hybrid glass/PTFE fabric, Composites Science and Technology, 67(6), 981-988, 2007

[7] Burris DL, Sawyer WG. A low friction and ultra low wear rate PEEK/PTFE composite, ,Wear 261, 410418, 2006.

[8] Suresh B, ShivaKumar K, Seetharamu S, SampathKumaran P. Friction and dry sliding wear behavior of carbon and glass fabric reinforced vinylester composites. Tribology International 43, 602-609, 2010.

[9] El-Tayeba N.S.M., A study on the potential of sugarcane fibers/polyester composite for tribological applications. Wear, Volume 265(1-2) 25, 223-235, 2008

[10] Hooke C.J., Kukureka S.N., Liao P., Rao M., Chen Y.K., The friction and wear of polymers in nonconformal contacts, Wear, 200(1-2), 83-94, 1996.

[11] Kukureka S.N., Chen Y.K., Hooke C.J., Liao P., The wear mechanisms of acetal in unlubricated rolling - sliding contact, Wear, 185(1-2), 1-8, 1995.

[12] Gordona D.H., Kukureka S.N., The wear and friction of polyamide 46 and polyamide 46/aramid-fibre, composites in sliding-rolling contact, Wear, 267(1-4), 669-678, 2009.

[13] Chena Y.K., Modib O.P., Mhaya A.S., Chrysanthou A., O'Sullivan J.M., The effect of different metallic counterface materials and different surface treatments on the wear and friction of polyamide 66 and its composite in rolling-sliding contact, Wear, 255(1-6), 714-721, 2003.

[14] S Bahadur. The development of transfer layers and their role in polymer Tribology. Wear 245 (1-2), 9299, 2000. 